\title{
Obturator neuropathy
}

\author{
John Sison Tipton
}

Published online: 11 June 2008

(C) The Author(s) 2008

\begin{abstract}
Obturator neuropathy is a difficult clinical problem to evaluate. One possible cause of pain is due to fascial entrapment of the nerve. Symptoms include medial thigh or groin pain, weakness with leg adduction, and sensory loss in the medial thigh of the affected side. Radiographic imaging provides limited diagnostic help. MRI may detect atrophy in the adductors of the leg. However, it is unable to detect any abnormality of the nerve or in the fibro-osseus tunnel. The best test for diagnosis is by electromyography (EMG) and can be confirmed by a local nerve block. Pharmacologic management of pain and physical therapy can be helpful in the acute phase of injury. Surgical decompression of the nerve should be considered for lesions documented by EMG or local nerve block, for those with predisposing risk factors (prior surgery, pelvic trauma, or hematoma) and with prolonged or severe lesions.
\end{abstract}

Keywords Obturator neuropathy · Obturator nerve

\section{Introduction}

Persistent pain in the groin and thigh area is a difficult clinical problem to evaluate. There are many entities that produce groin pain including tendonitis, bursitis, osteitis pubis, stress fracture, sports hernias or athletic pubalgia, nerve entrapment [1-3]. In some instances, a report of obturator nerve compression, specifically its anterior division, is one possible cause of pain in the adductor region [4].

\section{J. S. Tipton $(\bowtie)$}

Memorial Family Medicine, 714 N. Michigan St.

South Bend, IN 46601, USA

e-mail: jtnobles@hotmail.com
Entrapment of the obturator nerve has been documented by nerve conduction studies [4]. Subsequent surgical decompression of the anterior division of the obturator nerve has produced favorable results [4]. The purpose of this article is to describe the various causes of obturator neuropathy, diagnostic tests, as well as various treatment modalities.

\section{Search strategy}

A literature search for this article was performed on PubMed. Key words used for the search were: obturator neuropathy and obturator nerve. A total of 497 articles were found. Of these, thirty articles were used in writing this manuscript. None of the articles were randomized controlled trials. One study was a retrospective cohort design that studied conservative medical management versus surgery. Another study was an experimental design using cadaver limbs. There were three review articles of which two used more than three case reports. The majority of the other studies used were case reports. Four were book chapters.

\section{Anatomy}

The obturator nerve originates from the anterior division of the ventral rami of the second, third, and fourth lumbar spinal nerves within the psoas major muscle. The obturator nerve results from the unification of the rami and descends through the psoas muscle to emerge from its medial border at the pelvic brim. It runs over the pelvic brim into the lesser pelvis, curving anteroinferiorly and following the lateral pelvic wall to pass through the obturator foramen in which it divides into anterior and posterior branches: the anterior branch innervates the adductor longus, gracilis, and adductor brevis muscles and also gives off sensory fibers that innervate the skin and fascia of the medial aspect 
of the midthigh. The posterior division pierces and innervates the obturator externus. Then it runs between the adductor brevis and magnus muscles and splits into a motor branch that supplies adductor magnus, and a sensory branch to the knee joint to supply the articular capsule, cruciate ligaments, and synovial membrane of the knee joint. The posterior branch occasionally innervates the adductor brevis $[5,6]$.

\section{Clinical presentation}

The most common presenting symptom is sensory alteration in the medial thigh $[5,7]$. These symptoms can include paresthesias, sensory loss, or pain [5]. The most frequent reported symptom in one study was medial thigh or groin pain [8]. A deep ache may be described in the adductor origin region at the pubic bone and may extend to the medial aspect of the thigh to the knee [5]. Exacerbation of pain may be caused by maneuvers that stretch the nerve either by extension or lateral leg movement [9]. There is also possibly diminished sensation along the medial thigh. In some instances, these sensory complaints may extend to the medial calf. However, the obturator nerve very rarely provides sensation distal to the knee [5, 7].

Despite the fact that many muscles used in thigh adduction are intervated by nerves other than the obturator $\mathrm{n}$. adduction on the affected side is usually weak. Sometimes medial thigh wasting can be observed [5]. With severe injuries, loss of adduction and internal rotation occur. During ambulation, the hip is externally rotated and abnormally abducted, which results in a circumducting, wide based gait [7, 10]. Ipsilateral loss of the hip adductor tendon reflex can be present, but is only suggestive, not pathognomonic of obturator neuropathy. Because this reflex does not always occur in healthy individuals, presence of this reflex on the contralateral, asymptomatic leg must occur for the finding to be useful [5].

\section{Causes}

The obturator nerve is rarely injured in isolation. Several authors have described injury to the nerve following surgery, hemorrhage, or tumor compression [11-25]. However, for the purpose of this article, the discussion will be limited to sports-related injuries.

Bradshaw et al. described obturator neuropathy in athletes as a result of fascial entrapment as the nerve enters the thigh, specifically in the adductor compartment [4]. Induced by exercise, the pain had a characteristic clinical pattern of medial thigh pain commencing in the region of the adductor muscle origin and radiating distally along the medial thigh, with strenuous exercise. An anatomic study on cadaver limbs by Harvey and Bell reinforced the concept that obturator neuropathy is caused by an entrapment syndrome due to the relationship between nerve, vessels, and fascia [26]. Brukner and Khan state that there may be "associated weakness or a feeling of a lack of propulsion of the limb during running but numbness is very rarely reported" [27]. Denervation of the adductor muscles was demonstrated by needle electromyography [4]. Conservative medical management has met with limited success. Conservative management included rest, physical therapy (such as ultrasound and interferential treatment), soft tissue massage, adductor muscle and pelvic strengthening exercises, oral anti-inflammatory therapy, corticosteroid injection, and groin stretches. Conversely, surgical neurolysis provided better outcomes with athletes returning to competition within several weeks of treatment. At surgery, entrapment of the obturator nerve by a thick fascia overlying the short adductor muscle was described. However, reproduction of this postulated entrapment neuropathy by other investigators has yet to be found.

\section{Diagnostic tests}

Plain radiographic studies are normal in persons exhibiting obturator neuropathy. However, there may be features found on radiograph that may identify a cause of groin pain other than obturator neuropathy. Magnetic resonance imaging (MRI) was used in a previous study to detect the distribution of local anesthetic during a three-in-one block [28]. MRI can also be used to obtain the baseline anatomical structure of the inguinal region of the patients in whom surgery is a possibility and to exclude other causes of groin pain [28]. MRI may detect atrophy of the adductor brevis and longus and gracilis suggestive of denervation and obturator nerve entrapment. However, it is unable to detect any abnormality of the nerve in the thigh or in the fibro-osseus tunnel [4]. Other imaging such as computed tomography or ultrasound imaging can be helpful for suspected intrapelvic mass lesions entrapping the obturator nerve $[5,7]$. Scintigraphic bone scan can demonstrate a mild ipsilateral increase in uptake in the region of the pubic ramus, at the origin of the short or long adductor muscle. But since obturator neuropathy is primarily a soft tissue problem, MRI is typically higher yield [4].

Perhaps the best test to confirm obturator neuropathy is needle electromyography (EMG). Bradshaw et al. showed chronic denervation in the short and long adductor muscles of athletes with chronic groin pain attributed to obturator neuropathy [4]. Other authors noted the importance that denervation findings (fibrillation potentials or high-amplitude, long-duration complex motor unit potentials) should be consistent with acute or chronic denervation in the hip adductors, but not in other lower extremity muscles such as the iliopsoas or quadriceps muscles [29]. Bradshaw et al. 
showed that paraspinal muscle sampling at L-2, L-3 and L-4 and in other muscles supplied by these nerve roots were normal, excluding a more proximal lesion. Nerve conduction studies of the other branches of the lumbosacral plexus were normal [4].

Previous authors have tested the validity of applying a local anesthetic block such as lidocaine or bupivacaine to the obturator nerve at the obturator foramen under fluoroscopy [30, 31]. It is proposed that the nerve block should reproduce the patient's weakness, especially after exercise, and should relieve pain from provocative stretches [4]. Presence of paresthesia in the sensory distribution of the obturator nerve over the distal medial thigh provides evidence of accurate localization and adequacy of the nerve block. If definitive surgical treatment is considered, this test is particularly useful to confirm the diagnosis of obturator involvement and especially useful in delineating between other possible causes of groin pain [4].

\section{Treatment}

Pharmacologic management of pain and physical therapy to improve strength and to preserve mobility and ambulation may be indicated. Medication can include non-steroidal anti-inflammatory drugs (NSAID) or other pain relievers such as acetaminophen. Rest, modification of the activities that initially caused the event, or substituting them with other activities may offer relief. Physical therapy, massage, or nerve blocks can all be tried. However, conservative management may not be a suitable alternative to the high level athlete or in those with refractory treatment.

There may be a temporal relationship between nerve injury, therapy, and recovery. Therefore athletes with diagnosed obturator neuropathy should try only a limited course of conservative therapy. Sorenson et al. stated that patients with acute onset of obturator neuropathy had good recovery with conservative management. Conversely, those with chronic neuropathy have less chance for improvement and, thus, result in a poorer outcome [8].

Surgery should be considered in those with pain and weakness resistant to conservative therapy and documented EMG changes or response to nerve block. Good outcomes have been reported after surgical release along the course of the nerve [4]. A rehabilitation plan of physical therapy with gradual return to activities after surgery should be implemented with expected return to activity at 3-6 weeks [4].

\section{Summary}

Mononeuropathies of the obturator nerve are rare. Athletes will present with pain, weakness in leg adduction, and sensory loss over a small area in the medial thigh sometimes just with exercise or exacerbated after exercise. Often, obturator neuropathy is caused by pelvic trauma or surgery so athletes should be questioned regarding previous surgery. Definitive diagnosis is made with electrophysiologic studies and can be confirmed by obturator nerve block with local anesthesia. Conservative therapy can be helpful in athletes with acute symptoms. Surgical exploration should be considered for lesions documented by EMG or local nerve block, for those with predisposing risk factors (prior surgery, pelvic trauma, or hematoma) and with prolonged or severe lesions.

Open Access This article is distributed under the terms of the Creative Commons Attribution Noncommercial License which permits any noncommercial use, distribution, and reproduction in any medium, provided the original author(s) and source are credited.

\section{References}

1. Ashby EC. Chronic obscure groin pain is commonly caused by enthesopathy: 'Tennis elbow' of the groin. Br J Surg. 1994;81: 1632-4.

2. Martens MA, Hansen L, Mulier JC. Adductor tendonitis and musculus rectus abdominis tendonopathy. Am J Sports Med. 1987;15:353-6.

3. Zimmerman G. Groin pain in athletes. Aust Fam Physician. 1988;17:1046-52.

4. Bradshaw C, McCrory P, Bell S, Brukner P. Obturator neuropathy: a cause of chronic groin pain in athletes. Am J Sports Med. 1997;25:402-8.

5. Stewart JD. Focal peripheral neuropathies. 2nd ed. New York: Raven Press; 1993.

6. Sunderland S. Nerves and nerve injuries, 2nd ed. Edinburgh: Churchill Livingstone; 1978.

7. Dawson DM, Hallet M, Wilbourn AJ. Miscellaneous uncommon syndromes of the lower extremity. In: Entrapment neuropathies. 3rd ed. Philadelphia: Lippincott-Raven; 1988, p. 369-79.

8. Sorenson EJ, Chen JJ, Daube JR. Obturator neuropathy: causes and outcome. Muscle Nerve. 2002;25(4):605-7.

9. Busis NA. Entrapment and other focal neuropathies. Neurol Clin. 1999;17(3):633-53.

10. Mumenthaler M, Schliack H. Lesions of individual nerves of the lower limb plexus and the lower extremity. In: Peripheral nerve lesions. Diagnosis and therapy. New York: Thieme Medical Publishers; 1991, p. 297-343.

11. Pavlov H, Nelson TL, Warren RF, Torg JS, Burstein AH. Stress fractures of the pubic ramus. A report of twelve cases. J Bone Joint Surg Am. 1982;64A:1020-5.

12. Barrick EF. Entrapment of the obturator nerve in association with a fracture of the pelvic ring of the pelvic ring. A case report. J Bone Joint Surg Am. 1998;80A:258-61.

13. Bischoff $\mathrm{C}$, Schonle PW. Obturator nerve injuries during intraabdominal surgery. Clin Neurol Neurosurg. 1991;93(1):73-6.

14. Crews DA, Dohlman LB. Obturator neuropathy after multiple genitourinary procedures. Urology. 1987;29:504-5.

15. Melamed NB, Satya-Murti S. Obturator neuropathy after total hip replacement. Ann Neurol. 1983;13:578.

16. Pellegrino MJ, Johnson EW. Bilateral obturator nerve injuries during urologic surgery. Arch Phys Med Rehabil. 1988;69:46-7. 
17. Schmalzried TP, Amstutz HC, Dorey FJ. Nerve palsy associated with total hip replacement: risk factors, prognosis. J Bone Joint Surg Am. 1991;73A:1074.

18. Silinski JM, Scott RD. Obturator-nerve palsy resulting from intrapelvic extrusion of cement during total hip replacement: report of four cases. J Bone Joint Surg Am. 1985; 67A:1225-8.

19. Weber ER, Daube JR, Coventry MB. Peripheral neuropathies associated with total hip arthroplasty. J Bone Joint Surg Am. 1976;58A:66-9.

20. Fishman JR, Moran ME, Carey RW. Obturator neuropathy after laparoscopic pelvic lymphadenectomy. Urology. 1993;42:198.

21. Finan MA, Fiorica JV, Hoffman MS, et al. Massive pelvic hemorrhage during gynecologic cancer surgery: "Pack and go back". Gynecol Oncol. 1996;62:390.

22. Clark JMP. Obstetrical palsy. J Bone Joint Surg Br. 1965;47B:806.

23. Bjork KJ, Mucha P Jr, Cahill DR. Obturator hernia. Surg Gynecol Obstet. 1988;167:217-22.

24. Redwine DB, Sharpe DR. Endometriosis of the obturator nerve: a case report. J Reprod Med. 1990;35:434.
25. Kent KC, Moscucci M, Gallagher SG, DiMattia ST, Skillman JJ. Neuropathy after cardiac catheterization: incidence, clinical patterns, and long-term outcome. J Vasc Surg. 1994; 19:1008.

26. Harvey G, Bell S. Obturator neuropathy. An anatomic perspective. Clin Orthop Relat Res. 1999; 363:203-11.

27. Brukner P, Khan KM. Clinical sports medicine. Sydney: McGraw-Hill; 1993, p. 302-15.

28. Marhofer P, Nasel C, Sitzwohl C, Kapral S. Magnetic resonance imaging of the distribution of local anesthetic during the three-inone block. Anesth Analg. 2000;90:119-24.

29. Kimura J. Electrodiagnosis in diseases of nerve and muscle: principles and practice. 2nd ed. Philadelphia: FA Davis; 1989, p. 506-9.

30. Felsenthal G. Nerve blocks in the lower extremities: anatomical considerations. Arch Phys Med Rehabil. 1974;55:504-7.

31. Magora F, Rozin R, Ben-Menachem Y, Magora A. Obturator nerve block. An evaluation of technique. Br J Anaesth. 1969;41: $695-8$. 